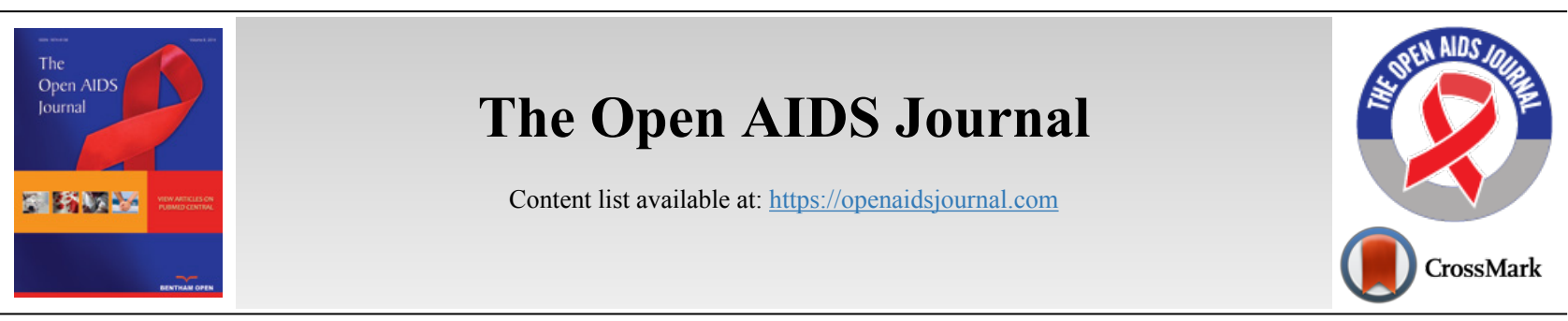

RESEARCH ARTICLE

\title{
Attitudes Toward Caring for People Living with HIV/AIDS: A Cross-Sectional Study of Nursing Faculty in Six Countries
}

Juan. M. Leyva-Moral ${ }^{1,2,3}$, Karen A. Dominguez-Cancino ${ }^{3,4,5}$, Joan E. Edwards ${ }^{6}$, David Moriña-Soler ${ }^{7}$, Sandra K. Cesario $^{6}$, Genesis M. Guevara-Vasquez, ${ }^{3,8,9}$, Maria Feijoo-Cid ${ }^{2}$ and Patrick A. Palmieri, ${ }^{3,8,10, *}$

${ }^{\prime}$ Grup de Recerca Infermera en Vulnerabilitat i Salut, Universitat Autònoma de Barcelona, Barcelona, Spain

${ }^{2}$ Department d'Infermeria, Universitat Autònoma de Barcelona, Barcelona, Spain

${ }^{3}$ Evidence-Based Health Care South America: A Joanna Briggs Institute Affiliated Group, Lima, Perú

${ }^{4}$ Escuela de Enfermería, Universidad Cientifica del Sur, Lima, Perú

${ }^{5}$ Escuela de Salud Pública, Universidad de Chile, Santiago, Chile

${ }^{6}$ Center for Global Nursing, Texas Woman's University, Houston, United States

${ }^{7}$ Departament de Matemàtiques, Universitat Autònoma de Barcelona, Barcelona, Spain

${ }^{8}$ Vicerrectorado de Investigación, Universidad Norbert Wiener, Lima, Perú

${ }^{9}$ Dirección de Investigación, Hospital Regional Lambayeque, Chiclayo, Perú

${ }^{10}$ College of Graduate Health Studies, A. T. Still University, Kirksville, United States

\begin{abstract}
:
Background:

Since the earliest study about nursing faculty and student attitudes about caring for people living with HIV/AIDS (PLHIV) in 1992, there have been less than 20 additional studies reported in the literature. Yet, PLHIV continues to report stigma and experience discrimination. Nursing faculty attitudes are part of the informal curriculum. Negativity about caring for PLHIV can adversely impact student perceptions as well as their care. Current research in this area is essentially non-existent.

Objective:

To describe the attitudes of the university nursing faculty toward caring for PLHIV; and to identify the relationship between faculty attitudes and explanatory factors such as age, education, religion, nationality, teaching in a clinical setting, years of experience, and university attributes.

Methods:

This was a multicenter cross-sectional study with nonrandomized electronic purposeful sampling. The Healthcare Provider HIV/AIDS Stigma Scale (HPASS) is a 30-item scale with three subscales: Prejudice, stereotype, and discrimination. The English and Spanish versions of the HPASS exhibit stable psychometric properties for cross-cultural research. The HPASS was delivered to university nursing faculty in six countries across three continents.

Results:

A sample of 368 nursing faculty completed the HPASS. The mean composite score was $2.41(\mathrm{SD}=0.69)$, six-point scale with lower scores indicating more positive attitudes, with subscale scores: Stereotypes $2.55(\mathrm{SD}=0.84)$, discrimination $2.28(\mathrm{SD}=0.74)$, and prejudices $2.41(\mathrm{SD}=$ 0.63). Peruvian faculty had the highest scores while Canadian had the lowest. Significant correlations were observed between attitudes and the three subscales, and between the three subscales and the composite score.

\section{Conclusion:}

Attitudes of the nursing faculty toward caring for PLHIV were slightly positive to slightly negative depending on the region and country. Knowledge deficiencies about HIV persist, incorrect beliefs are common, and attitudes appear to be influenced by culture. The correlation between subscales justifies continued research to implement targeted interventions. Education about HIV/AIDS can address knowledge deficits while structured interactions with PLHIV can facilitate experiential learning.
\end{abstract}

Keywords: Acquired Immunodeficiency Syndrome, HIV Infections, Faculty, Nursing, Social Stigma, Social Discrimination, Prejudice, Healthcare Provider HIV/AIDS Stigma Scale, HPASS. 
Article History

Received: April 16, 2020

\section{INTRODUCTION}

Nearly 40-years have passed since the first cases of acquired immune deficiency syndrome (AIDS) were reported [1] and the human immunodeficiency virus (HIV) was isolated as the causative agent [2]. Advancements in clinical management strategies, including new pharmaceuticals, have shifted the associated AIDS from an acute and lethal illness to a chronic but manageable condition. However, reductions in prejudices, stereotypes, and discrimination have not paralleled clinical improvements. As a result, people living with HIV/AIDS (PLHIV) continue to experience substantial stigmatization and overt discrimination [3, 4].

Immediately following the discovery of HIV/AIDS, the media reported negative reactions among health professionals as they avoided caring for PLHIV, fearing the contagion $[5,6]$. Although evidence suggests there has been a steady decline in discriminatory behaviors fears about contracting HIV continue to linger in nursing faculty [7 -9], especially when patients are homosexual or intravenous drug users $[10,11]$. There were positive correlations between negative attitudes toward caring for PLHIV and age, homophobia, having children [12], and religion and race [7]. However, positive nursing attitudes are necessary for respectful, compassionate, and understanding care [13].

\subsection{HIV Stigma Framework}

The HIV Stigma Framework [14] explains how PLHIV encounter stigmatizing situations resulting from prejudices, stereotypes, and discrimination [15]. Stigma exists as a social structure with interpersonal processes that reduces the social value and the standing of people [16] due to their HIV positive status [17]. Prejudices are the negative attitudes toward a group or members of a group [18], whereas stereotypes are the general social beliefs that are then uniformly applied to all members [19]. Discrimination, however, goes beyond mere attitudes with negative behaviors directed at members of a group, or results in less positive behaviors targeted to a specific group member with similar situations as other members [20]. With persistent stigmatizing experiences, PLHIV are vulnerable to emotional, cognitive, and behavioral damage [17]. Although health care institutions should be safe environments for PLHIV [21], most health care professionals are often unaware of their stigmatizing attitudes and behaviors $[22,23]$.

\subsection{Nursing Students}

Nursing students are not exempt from the fear of contagion as negative attitudes about caring for PLHIV persist, including refusing to administer basic care such as hygiene, shaving, and feeding in Turkey [24 - 27]. However, in Germany, Lohrmann et al. [28] reported positive attitudes among nursing students, especially among those who had previous contact with someone living with HIV/AIDS. Yet, most of the available

\footnotetext{
* Address correspondence to this author at the Vicerrectorado de Investigacion, Universidad Norbert Wiener, Avenida Arequipa 444, Torre 2, Piso 4, Lima, 15046, Perú;

E-mails: patrick.palmieri@jbisa.org or patrick.palmieri@uwiener. edu.pe
}

\begin{tabular}{l|l} 
Revised: July 22, 2020 & Accepted: July 28, 2020
\end{tabular}

evidence about the attitudes of student nurses in caring for PLHIV is old, possibly not reflecting the contemporary reality.

Since the earliest study about nursing faculty and student attitudes regarding caring for PLHIV [29], there have been less than 20 additional studies related to students and/or faculty reported in the literature (PubMed search strategy: ((()((()(((nurse) OR nursing) AND faculty) OR professor) OR instructor)) AND (((HIV) OR AIDS) OR HIV/AIDS))) AND ((((attitude) OR perception) OR perspective) OR belief $))$ AND ((((stigma) OR discrimination) OR stereotyping) OR prejudice). In addition, a few recent studies, cross-sectional with small samples, are contradictory. For example, Suominen et al. [30] found discriminatory attitudes among nursing students in Russia, while Leyva-Moral et al. [31], reported positive attitudes among two cohorts of nursing students in Spain. Larger multinational comparative studies are necessary to better understand the current situation across countries and different cultures.

\subsection{Nursing Faculty}

The attitudes of the university nursing faculty, or nursing faculty, are important as they can become part of the informal or 'occult curriculum' $[11,32,33]$; that is, there can be implicit learning impregnated with personal values $[34,35]$. Positive results about working with PLHIV have been reported among university faculty in general [36]; most positive in education [37] and dentistry faculty [38]. Leyva-Moral et al. [31] found that $79.8 \%$ of nursing faculty at a school in Spain indicated positive attitudes, especially among those who did not profess a religion. The results come from studies with small local samples using validated, though outdated, instruments. Evidence about the attituds of nursing faculty is essentially non-existent.

\subsection{Objective}

The purpose of this study was to understand the attitudes of the nursing faculty toward caring for PLHIV and to identify the relationship between attitudes and potential explanatory factors including age, education, religion, nationality, teaching in a clinical setting, years of experience, and university attributes.

\section{MATERIALS AND METHODS}

\subsection{Study Design}

This was an international multicenter cross-sectional study with a nonrandomized purposeful sample.

\subsection{Setting and Participants}

The schools of nursing from 30 universities were invited to participate from three targeted regions: North America, South America, Europe (Spain and England). Universities were chosen for ease of access to develop a diverse sample with English and Spanish speaking countries. About half the universities agreed to participate (2 Canada, 1 Colombia, 3 Peru, 8 Spain, 1 United Kingdom, 1 United States). The deans and department directors from each university shared the study 
information with their nursing faculty by email with a direct link to the anonymous questionnaire.

\subsection{Data Collection}

Data were collected with a digital version of the Healthcare Provider HIV/AIDS Stigma Scale, or HPASS [39] from September 2016 to July 2017. The HPASS is a 30 -item valid and reliable scale with three subscales: Prejudice, stereotype, and discrimination. The internal consistency and test-retest reliability for the overall scale (Cronbach's alpha between 0.88 and 0.94), and the three individual subscales (Cronbach's alpha between 0.80 and 0.93 ) are excellent $[39,40]$. Furthermore, in a cross-cultural scale translation study of Chinese and Canadian medical students, the content validity index average was 0.88 , while the ICC was 0.87 [40]. As the instrument incorporates a six-point Likert scale, ranging from complete disagreement (1) to complete agreement (6) (the lower the score, the more positive attitude) in response to statements about attitudes and beliefs regarding PLHIV, ambiguous midline responses are eliminated [39]. A Spanish version, or HPASS-ESP [41], was produced for Peru. Colombia, and Spain using forward and reverse translation, with expert assessment and correction for context, content, and culture [42]. - see the supplemental file for the complete HPASS-ESP instrument. The assessment was completed by 12 nursing faculty in three different Spanish-speaking countries. In addition to the HPASS, sociodemographic data were collected.

\subsection{Ethical Considerations}

Before being able to complete the digital questionnaire, each nursing faculty was required to review the introductory information about the study, including detailed information about the research team, aim of the study, time for completion, and risks and benefits. As such, the nursing faculty were able to make an informed decision prior to agreeing to participate by entering the questionnaire. Participation was voluntary, anonymous, and without compensation for participating. Physical data and records, although without identifying information, were maintained in a safe locked file accessible only to the research team while digital data was secured through password protected programs on a secure server. The study was approved by the university institutional review board (Protocol \#19213).

\subsection{Data Analysis}

Descriptive information for all explanatory and response variables are provided as $\mathrm{n}(\%)$ or mean (standard deviation). The association of the explanatory variables and outcomes (composite score and subscale scores) was determined through linear modeling [43]. The models included the subscale scores, the composite score as a response variable, and the explanatory variables. The factors significantly associated with the outcome, the direction of the association, and the strength of the relationship emerged from the modeling. Also, a sensitivity analysis was completed, accounting for potential clustering across the six countries $[44,45]$. Finally, a correlation analysis was completed to measure the direction and strength of potential associations across the three considered subscales (Altman, 1991). All analyses were conducted using $\mathrm{R}$ version 3.4.1 [46] and Stata 14.0 [47]. The study is reported according to the STROBE (Strengthening the Reporting of Observational Studies in Epidemiology), following the minimum requirements for reporting cross-sectional studies [48].

\section{RESULTS}

A total of 368 nursing faculty from Canada, Colombia, Peru, Spain, United States, and United Kingdom responded to the HPASS questionnaire. The mean age of the participants was 47.5 years $(\mathrm{SD}=11.0)$ and the majority self-identified as female $(280 ; 76.1 \%)$. Nursing faculty reported an average teaching experience of 13.2 years $(\mathrm{SD}=10.8)$; most with completed postgraduate studies $(36.5 \%$ held a doctoral degree and $45.3 \%$ had a master's degree). Participants primarily taught at the undergraduate level $(256 ; 70.9 \%)$. For the most part, the participants self-identified as Catholic (190; 54.0\%), and nearly half indicated religion was either 'important' or 'very important' in their lives $(174 ; 47.8 \%)$. An additional $25.3 \%$ (89) of the participants self-identified as agnostic/ atheists (Table 1).

Table 1. Participant Descriptive Data (mean and standard deviation).

\begin{tabular}{|c|c|c|}
\hline Socioeconomic Information (mean/SD) & n (\%) & $\mathbf{N}$ \\
\hline Gender & & 368 \\
\hline Male & $88(23.90)$ & \\
\hline Female & $280(76.10)$ & \\
\hline Age & $47.5(11.00)$ & 362 \\
\hline Religion & & 352 \\
\hline Catholic & $190(54.00)$ & \\
\hline Agnostic/Atheist & $89(25.30)$ & \\
\hline Other & $73(20.73)$ & \\
\hline Importance of Religion & & 364 \\
\hline Very important & $98(26.90)$ & \\
\hline Important & $76(20.90)$ & \\
\hline Somewhat important & $51(14.00)$ & \\
\hline Not important & $46(12.60)$ & \\
\hline Not important at all & $80(22.00)$ & \\
\hline
\end{tabular}




\begin{tabular}{|c|c|c|}
\hline I prefer not to answer & $13(3.57)$ & \\
\hline Highest Academic Degree Achieved & & 364 \\
\hline Doctoral & $133(36.50)$ & \\
\hline Master & $165(45.30)$ & \\
\hline Nurse Specialist & $29(7.97)$ & \\
\hline Advanced Practitioner & $5(1.37)$ & \\
\hline Registered Nurse & $27(7.42)$ & \\
\hline I prefer not to answer & $5(1.37)$ & \\
\hline Working as Clinical and Faculty & & 366 \\
\hline Yes & $180(49.2)$ & \\
\hline No & $182(49.7)$ & \\
\hline I prefer not to answer & $4(1.09)$ & \\
\hline Teaching Level & & 361 \\
\hline Doctoral & $17(4.71)$ & \\
\hline Master & $24(6.65)$ & \\
\hline Undergraduate & $256(70.90)$ & \\
\hline Both & $60(16.60)$ & \\
\hline I prefer not to answer & $4(1.11)$ & \\
\hline Teaching Experience, Years (mean/SD) & $13.2(10.80)$ & 323 \\
\hline Country: & & 360 \\
\hline USA & $65(18.10)$ & \\
\hline Colombia & $44(12.20)$ & \\
\hline Spain & $145(40.30)$ & \\
\hline UK & $22(6.110)$ & \\
\hline Peru & $63(17.50)$ & \\
\hline Canada & $21(5.830)$ & \\
\hline Type of University & & 360 \\
\hline Private & $229(63.60)$ & \\
\hline Public & $131(36.40)$ & \\
\hline HPASS composite score & $2.41(0.69)$ & 339 \\
\hline Stereotyping subscale score & $2.55(0.84)$ & 339 \\
\hline Discrimination subscale score & $2.28(0.74)$ & 337 \\
\hline Prejudices subscale score & $2.41(0.63)$ & 338 \\
\hline
\end{tabular}

Table 2. HPASS composite score and subscale scores (means and standard deviations).

\begin{tabular}{|c|c|c|c|c|c|c|}
\hline & $\begin{array}{c}\text { USA } \\
\mathbf{N}=\mathbf{6 0}\end{array}$ & $\begin{array}{c}\text { Colombia } \\
\mathbf{N = 4 2}\end{array}$ & $\begin{array}{c}\text { Spain } \\
\mathbf{N = 1 3 2}\end{array}$ & $\begin{array}{c}\text { UK } \\
\mathbf{N = 2 1}\end{array}$ & $\begin{array}{c}\text { Canada } \\
\mathbf{N}=\mathbf{5 7}\end{array}$ \\
\hline HPASS & $2.44(0.60)$ & $2.44(0.64)$ & $2.28(0.57)$ & $2.03(0.63)$ & $3.05(0.68)$ & $1.83(0.43)$ \\
\hline Stereotype & $2.60(0.76)$ & $2.52(0.78)$ & $2.39(0.68)$ & $2.15(0.98)$ & $3.36(0.73)$ & $1.89(0.68)$ \\
\hline Discrimination & $2.31(0.61)$ & $2.35(0.74)$ & $2.14(0.64)$ & $1.88(0.63)$ & $2.91(0.82)$ & $1.70(0.37)$ \\
\hline Prejudice & $2.43(0.64)$ & $2.51(0.68)$ & $2.32(0.52)$ & $2.10(0.62)$ & $2.81(0.68)$ & $1.96(0.21)$ \\
\hline
\end{tabular}

Overall, the HPASS responses resulted in a mean composite score of $2.41(\mathrm{SD}=0.69)$. The subscale mean scores were $2.55(\mathrm{SD}=0.84)$ for stereotypes, $2.28(\mathrm{SD}=0.74)$ for discrimination, and $2.41(\mathrm{SD}=0.63)$ for prejudices (Table 2$)$. By country, the highest mean composite and subscale scores were observed among Peruvian nursing faculty and the lowest among Canadian faculty.

Linear analysis indicates for all faculty from all the universities, except for Colombia and Peru, the composite scores and subscales were lower to the reference university (USA) (Table 2). Canadian nursing faculty showed statistical significance in both the total HPASS $(\mathrm{p}=0.002)$ and the three subscales (prejudice $\mathrm{p}=0.009$; discrimination $\mathrm{p}=0.006$; stereotypes $\mathrm{p}=0.007)$. The Peruvian nursing faculty scores were significantly higher in both the total HPASS $(p=0.001)$ and its 3 subscales (prejudice $\mathrm{p}=0.006$; discrimination $\mathrm{p}=$ 0.001 ; stereotypes $\mathrm{p}=0.001)($ Table 3$)$.

The results of the total HPASS were significantly higher in public universities $(p=0.038)$ as opposed to private universities. As for the prejudice subscale, significantly lower scores were observed in the participants self-identifying as advanced nurse practitioners $(\mathrm{p}=0.032)$. In public 
Table 3. Explanatory variables associated with each subscale and the HPASS composite score.

\begin{tabular}{|c|c|c|c|c|c|c|c|c|c|}
\hline & & \multicolumn{2}{|l|}{ HPASS } & \multicolumn{2}{|c|}{ PREJUDICES } & \multicolumn{2}{|c|}{ DISCRIMINATION } & \multicolumn{2}{|c|}{ STEREOTYPES } \\
\hline & & $\begin{array}{l}\text { Estimate (Std. } \\
\text { error) }\end{array}$ & p-value & $\begin{array}{l}\text { Estimate (Std. } \\
\text { error) }\end{array}$ & p-value & Estimate (Std. error) & p-value & $\begin{array}{l}\text { Estimate (Std. } \\
\text { error) }\end{array}$ & $\mathrm{p}$-value \\
\hline Age & & $0.01(0.01)$ & 0.094 & $0(0)$ & 0.44 & $0.01(0.01)$ & 0.095 & $0.01(0.01)$ & 0.123 \\
\hline \multirow{5}{*}{ Education } & Doctoral & $0.14(0.09)$ & 0.14 & $0.01(0.09)$ & 0.873 & $0.15(0.1)$ & 0.164 & $0.2(0.12)$ & 0.041 \\
\hline & Master & $0.21(0.17)$ & 0.212 & $0.11(0.16)$ & 0.504 & $0.19(0.18)$ & 0.303 & $0.28(0.21)$ & 0.186 \\
\hline & Nurse Specialist & $-0.05(0.43)$ & 0.913 & $0.26(0.42)$ & 0.528 & $-0.02(0.48)$ & 0.964 & $-0.25(0.55)$ & 0.647 \\
\hline & $\begin{array}{l}\text { Advanced } \\
\text { Practitioner }\end{array}$ & $-0.18(0.15)$ & 0.243 & $-0.32(0.15)$ & 0.032 & $-0.23(0.17)$ & 0.178 & $-0.05(0.2)$ & 0.797 \\
\hline & $\mathrm{RN}$ & $0.94(0.62)$ & 0.127 & $0.91(0.59)$ & 0.126 & $1.24(0.68)$ & 0.072 & $0.61(0.78)$ & 0.436 \\
\hline Religion & Religious & $-0.08(0.13)$ & 0.515 & $0.06(0.12)$ & 0.654 & $-0.16(0.14)$ & 0.28 & $-0.07(0.16)$ & 0.647 \\
\hline \multirow{4}{*}{$\begin{array}{l}\text { Importance of } \\
\text { religion }\end{array}$} & Important & $-0.03(0.11)$ & 0.8 & $0.09(0.11)$ & 0.401 & $-0.01(0.12)$ & 0.948 & $-0.12(0.14)$ & 0.41 \\
\hline & $\begin{array}{l}\text { Somewhat } \\
\text { important }\end{array}$ & $-0.01(0.13)$ & 0.958 & $0.24(0.13)$ & 0.065 & $-0.07(0.15)$ & 0.66 & $-0.07(0.17)$ & 0.663 \\
\hline & Not important & $-0.16(0.14)$ & 0.249 & $0.08(0.14)$ & 0.581 & $-0.21(0.16)$ & 0.193 & $-0.24(0.18)$ & 0.173 \\
\hline & $\begin{array}{l}\text { Not important at } \\
\text { all }\end{array}$ & $-0.43(0.16)$ & 0.009 & $-0.1(0.15)$ & 0.502 & $-0.44(0.18)$ & 0.015 & $-0.58(0.2)$ & 0.004 \\
\hline \multirow{5}{*}{ Country } & Colombia & $-0.01(0.16)$ & 0.962 & $0.05(0.15)$ & 0.76 & $0.04(0.17)$ & 0.835 & $-0.08(0.2)$ & 0.688 \\
\hline & Spain & $-0.31(0.21)$ & 0.133 & $-0.28(0.2)$ & 0.168 & $-0.29(0.23)$ & 0.208 & $-0.36(0.26)$ & 0.176 \\
\hline & UK & $-0.32(0.19)$ & 0.098 & $-0.27(0.19)$ & 0.148 & $-0.37(0.22)$ & 0.097 & $-0.3(0.24)$ & 0.214 \\
\hline & Peru & $0.57(0.14)$ & 0.001 & $0.38(0.14)$ & 0.006 & $0.56(0.16)$ & 0.001 & $0.7(0.18)$ & 0.001 \\
\hline & Canada & $-0.56(0.18)$ & 0.002 & $-0.46(0.17)$ & 0.009 & $-0.56(0.2)$ & 0.006 & $-0.62(0.23)$ & 0.007 \\
\hline Clinical setting & No & $0(0.09)$ & 0.967 & $0.14(0.09)$ & 0.104 & $-0.03(0.1)$ & 0.791 & $-0.04(0.11)$ & 0.735 \\
\hline $\begin{array}{c}\text { Years of } \\
\text { experience }\end{array}$ & & $0(0.01)$ & 0.646 & $0(0.01)$ & 0.983 & $0.01(0.01)$ & 0.246 & $0(0.01)$ & 0.86 \\
\hline $\begin{array}{l}\text { University } \\
\text { funding }\end{array}$ & Public & $0.4(0.19)$ & 0.038 & $0.36(0.18)$ & 0.049 & $0.39(0.21)$ & 0.064 & $0.42(0.24)$ & 0.078 \\
\hline
\end{tabular}

* Independent linear model for each subscale and composite score.

Table 4. Correlation analysis between the hpass subscales and the composite score.

\begin{tabular}{|c|c|c|}
\hline Scales and Composite & r & p-value \\
\hline Stereotype \& Discrimination & 0.77 & $<0.0001$ \\
\hline Stereotype \& Prejudice & 0.59 & $<0.0001$ \\
\hline Discrimination \& Prejudice & 0.70 & $<0.0001$ \\
\hline Total HPASS \& Stereotype & 0.92 & $<0.0001$ \\
\hline Total HPASS \& Prejudice & 0.77 & $<0.0001$ \\
\hline Total HPASS \& Discrimination & 0.94 & $<0.0001$ \\
\hline
\end{tabular}

universities, for the same subscale, significantly higher scores were observed $(p=0.045)$. In the "discrimination" subscale, significantly higher scores were observed among the registered nurses $(p=0.034)$. Finally, in the "stereotypes" subscale, significantly higher scores were observed among faculty holding a doctoral degree $(\mathrm{p}=0.041)$. There were no statistically significant findings related to the other variables (Table 3).

Correlational analysis showed a statistically significant association $(\mathrm{p}<0.001)$ between the three different subscales and between the scores of the subscales and the HPASS composite score (Table 4). Results from the sensitivity analysis, considering potential clustering across the six countries, did not differ from those obtained through other analyses.

\section{DISCUSSION}

Generally, the attitudes of the nursing faculty towards caring for PLHIV are slightly to solidly positive; however, there are notable differences between countries. In addition, there are specific areas for improvement in each country. Apart from Peru, the results are consistent with the findings reported in the few but recent investigations. For example, Leyva et al. [31] in a cross-section study with a small local nursing faculty sample, reported positive attitudes improving over time. Their study also revealed the persistent presence of false myths and the lack of knowledge about HIV/AIDS. Significantly better, more favorable, attitudes were identified among nursing faculty 
who reported having no religious beliefs. Furthermore, in a science faculty study in three universities in Venezuela, Méndez et al. [37] determined the skills and knowledge specific to PLHIV were unfavorable, the latter being significantly associated with older age $(\mathrm{p}<0.005)$. Attitudes toward PLHIV were favorable, although no significant differences were found in sociodemographic variables.

\subsection{Attitudes and Behaviors}

Positive attitudes are related to increased caring behaviors $[49,50]$. Nursing education has long played an important role in the development of caring attitudes [51], the acquisition of knowledge [52], and the advancement of caring behaviors [53]. According to Watson [54], for nurses caring is "the moral ideal of nursing whereby the end is protection, enhancement, and preservation of human dignity" (p. 29). However, negative nursing faculty attitudes towards caring for PLHIV can adversely impact the attitudes of students and the care they provide. The impact of nursing faculty attitude can be partly explained in relation to their comfort teaching content about specific populations. For example, Sirota [11] described " $a$ long skew toward negative attitudes" (p. 222). for more than half of the nursing faculty $(\mathrm{n}=733)$ regarding homosexuality. In this study, less than $30 \%$ of the faculty reported they were prepared to teach students about homosexuality with almost $90 \%$ indicating a "sense of ignorance about what content to teach and how to teach it" (p. 225). The implication is nursing faculty are not comfortable teaching what they do not understand.

\subsection{Graduate Education and Advance Practice}

The data from this study indicate that nursing faculty working as advanced practice nurses, or nurse practitioners, have the lowest "prejudice" subscale of all participants. Likewise, nursing faculty working as non-advanced practice registered nurses, including those with doctoral degrees, had the lowest subscale scores for "discrimination" and "stereotypes". Continuing education and professional development can impact the acquisition of knowledge and result in positive changes in attitudes. For example, Farley et al. [55] reported better, more favorable attitudes of caring for HIV-infected pregnant women among certified nurse practitioners as compared to registered nurses in a sample of 121 health care workers in the United States. However, significant differences were only found for the subscale about childcare $(\mathrm{p}=0.001)$. This finding can be explained by the advanced clinical education and the daily contact they have with PLHIV in clinical practice. Furthermore, Hamama et al. [56] reported a positive correlation with empathetic attitudes ( $\mathrm{r}$ $=0.36, \mathrm{P}<0.001)$ and negative significant correlation with avoidant attitudes $(\mathrm{r}=-0.34, \mathrm{P}<0.001)$ among the nurses working in specialized HIV/AIDS clinics in Russia, compared with those only working in general clinics. Daily work interactions between providers and PLHIV seem to result in more positive caring attitudes.

\subsection{South America, Culture, and Context}

In Peru, nursing faculty HPASS scores were higher than the other countries, including neighboring Colombia with the second highest scores. This may be due, among other reasons, to the high HIV-related stigma that exists in Latin America [57] and to the marked discrimination experienced by lesbian, gay, transgender, and bisexual people, or LGTB community [58]. In Latin America, there is a close relationship between machismo and the meanings associated with sexuality, and therefore to sexually transmitted infections such as HIV [59, $60]$. In the Latino community, ideas about machismo contribute to discrimination against women and gay men and enhance homophobia and sexual coercion [61]. The higher scores might be associated with the machismo prevailing in Peruvian society, including the health sector $[62,63]$, and therefore the discrimination experienced by the collective LGTB. Other investigations have found differences associated with religion $[7,31,64]$, not being the case in this study. These differences could be due to reasons of sampling and variability of sociocultural contexts in which participants share cultural meanings associated with sexuality and HIV but not with religious affiliation.

\subsection{Faculty and Student Caring Behaviors}

Nursing faculty caring behaviors can positively influence the caring behavior of students [65]. When nursing faculty exhibit positive attitudes and role model caring behaviors toward PLHIV, nursing students will manifest the same caring attitude and behaviors. Developing professional education for nursing faculty about caring for PLHIV is an essential strategy to advance positive and caring attitudes. According to Camillo et al. [66], nursing faculty need to develop critical and constructive approaches to teaching students about HIV/AIDS, including sharing personal experiences from PLHIV in classroom presentations and discussions. In this regard, FeijooCid et al. [67] concluded that the expert patient illness narrative is an effective teaching method, resulting in a high level of satisfaction among undergraduate nursing students. This method has shown satisfactory results in developing cultural sensitivity, respect, and trust in others [68].

\subsection{Mentoring and Education}

In a setting external to the classroom with experienced HIV nurses and PLHIV as mentors, Worthington et al. [69] reported rural Canadian nurses clinically managed HIV care and provided person-centered care to PLHIV. Through qualitative interviews, the participants reported positive changes in terms of knowledge, attitudes, and practices. Similarly, including PLHIV as simulated patients for teaching pretest and posttest HIV counselling in medical students reduced HIV-related stigma and increased comfort with providing HIV-related care [70]. In other educational settings, a population of Iranian schoolteachers $(\mathrm{n}=1.838)$, Hoseinpour et al. [71], reported educating teachers about general HIV/AIDS concepts resulted in a statistically significant improvements in attitudes about PLHIV. Similarly, Lohmann et al. [72] reported Belizean faculty from other academic settings were significantly more comfortable with PLHIV with prior experience teaching sexual topics and knowledge about HIV/AIDS. Knowledge deficits across a variety of settings suggests that knowledge deficits about sexually transmitted infections contribute to persistent myths about PLHIV. Social 
stigma, and discriminatory behavior, are important issues [36] from schoolteachers to health professionals and university faculty.

\subsection{Limitations and Strengths}

This study has several important limitations. First, this study used a self-administered questionnaire that can result in participants responding to what they believe is a desirable image [73]. However, this potential bias was reduced through the anonymous digital data collection. Second, the convenience samples in specific cities of the different countries might not represent the entire country. Also, the use of purposeful sampling strategy could have similarly influenced the results [74]. Despite this limitation, this study was the largest sample size reported in the literature and the only study that compared the context of different countries. As such, the potential for bias from the limitations is balanced with the heterogeneity in the socio-cultural and contextual reality of the participants. With this study, additional research, qualitative with semistructured interviews based on these findings, can further explore the attitudes from an individual perspective.

\section{CONCLUSION}

In general, attitudes of the nursing faculty towards caring for PLHIV were slightly positive, with specific subscales requiring improvement. Myths and knowledge deficits about HIV/AIDS remain problematic and the attitudes appear to be influenced by nationality. University faculty in nursing and the other health sciences need to take a critical but constructive approach to improving HIV/AIDS education, including the incorporation of real-world experiences with PLHIV in the classroom.

This is the first study to report a correlation between attitudes and the three dimensions (prejudices, discrimination, and stereotypes) among nursing faculty. In addition, there was a significant correlation between the three subscales and the HPASS composite. This finding justifies continued research with the HPASS to develop targeted interventions to address deficits. Since all the factors are related, an educational activity, for example, designed to improve attitudes, will impact the three dimensions.

Finally, there are three recommendations specific to future areas for research and practice. First, the inclusion of more participants from different universities in the countries represented in this study can improve the fidelity of the findings. Furthermore, including participants from additional countries in South America (e.g. Argentina, Bolivia, Chile, and Colombia) may provide more information about the impact of nationality, as well as culture, on the HPASS scores. Second, qualitative research is necessary to explain the reasons for the composite HPASS and subscale scores. For example, a qualitative study can directly explore the influence of nursing faculty attitudes on student attitudes and, more importantly, their behaviors in providing care for PLHIV. Finally, theoryderived, evidence-informed interventions need to be developed to advance the knowledge and attitudes of nursing faculty about caring for PLHIV. This study was necessary to understand the current situation prior to implementing targeted interventions to improve faculty attitudes about caring for PLHIV.

\section{LIST OF ABBREVIATIONS}

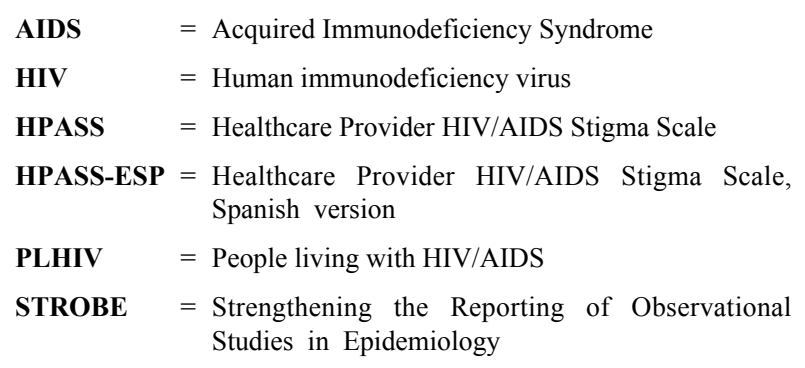

\section{AUTHORS' CONTRIBUTIONS}

All authors participated in the manuscript submitted for journal review. The following authors were involved in the stated phases of the project: Study conception (JLM); study design (JEE, JLM, PAP); data collection (JLM, SKS, JEE, SKC); data analysis (JLM, DMS, GGV, KDC, PAP); data interpretation (JEE, JLM, KDC, PAP); drafting the manuscript (DMS, JEE, JLM, MFC, PAP, SKC); table development (DMS, GGV, KDC); substantial revisions to the manuscript (JLM, KDC, PAP), critical revisions to the final manuscript (JLM, KDC, PAP); and senior scholar guidance (JEE, PAP, $\mathrm{SKC})$.

\section{ETHICS APPROVAL AND CONSENT TO PARTICIPATE}

This study was approved by the Institutional Review Board at Texas Woman's University, Texax, US (Protocol \#19213).

\section{HUMAN AND ANIMAL RIGHTS}

Not applicable.

\section{CONSENT FOR PUBLICATION}

Not applicable.

\section{AVAILABILITY OF DATA \& MATERIALS}

The datasets analyzed during the current study are available from the Open Science Framework at DOI: 10.17605/OSF.IO/GUA9K.

\section{FUNDING}

This project was partially supported through a research dissemination grant (VRI-D-2020-05-001-RDG) received from the Universidad Norbert Wiener by Dr. Patrick A. Palmieri to advance positive social change through promoting open source knowledge for low- and middle-income countries.

\section{CONFLICT OF INTEREST}

The authors declare no potential or existing conflicts of interest, financial or otherwise.

\section{ACKNOWLEDGEMENTS}

We would like to thank all our colleagues who helped with the data collection process: Dr. D. Ballester, Dr. M. Bennasar, 
Dr. D. Bernabeu, Dr. S. Campbell, Dr. F. de los Cobos, Dr. J. Fernández, Dr. A. Giménez, Dr. D. Gonzales, Dr. M. Lalinde, Dr. J. Lavado, Ms. N. Membrillo, Dr. J. Mendigure, Dra. G. Merán, Dr. A. Nibert, Dr. P. Pearson, Dr. I. Pérez, Ms. P. Piscoya, and Dr. J. Profetto. Without their invaluable contribution and selfless participation, this study would not have been possible. In addition, we want to thank Dr. Rosalie Mainous, Dean of the College of Nursing, Texas Woman's University and Dr. Maria Dolors Bernabeu-Tamayo, Director of the Departament d'Infermeria, Universitat Autònoma de Barcelona for their continued support of the Center for Global Nursing at the Texas Woman's University through funding faculty exchanges and facilitating the global research activities that stimulate research with practical implications for advancing evidence-based clinical practice in developing countries.

\section{SUPPLEMENTARY MATERIAL}

Supplementary material is available on the publishers website along with the published article.

\section{REFERENCES}

[1] Centers for Disease Control (CDC). Update on acquired immune deficiency syndrome (AIDS)--United States. MMWR Morb Mortal Wkly Rep 1982; 31(37): 507-508, 513-514.

[PMID: 6815471]

[2] Gallo RC, Salahuddin SZ, Popovic M, et al. Frequent detection and isolation of cytopathic retroviruses (HTLV-III) from patients with AIDS and at risk for AIDS. Science 1984; 224(4648): 500-3. [http://dx.doi.org/10.1126/science.6200936] [PMID: 6200936]

[3] Munro L, Marshall Z, Bauer G, Hammond R, Nault C, Travers R. (Dis)integrated care: Barriers to health care utilization for trans women living with HIV. J Assoc Nurses AIDS Care 2017; 28(5): 708-22. [http://dx.doi.org/10.1016/j.jana.2017.06.001] [PMID: 28838570]

[4] Wagner AC, Girard T, McShane KE, Margolese S, Hart TA. HIVrelated stigma and overlapping stigmas towards people living with HIV among health care trainees in Canada. AIDS Educ Prev 2017; 29(4): 364-76

[http://dx.doi.org/10.1521/aeap.2017.29.4.364] [PMID: 28825863]

[5] Associated Press. New York, NY: The New York Times 1987; 21.

[6] Associated Press. New York, NY: The New York Times 1987; 16.

[7] Stringer KL, Turan B, McCormick L, et al. HIV-related stigma among healthcare providers in the deep South. AIDS Behav 2016; 20(1): $115-25$.

[http://dx.doi.org/10.1007/s10461-015-1256-y] [PMID: 26650383]

[8] Vorasane S, Jimba M, Kikuchi K, et al. An investigation of stigmatizing attitudes towards people living with HIV/AIDS by doctors and nurses in Vientiane, Lao PDR. BMC Health Serv Res 2017; 17(1): 125.

[http://dx.doi.org/10.1186/s12913-017-2068-8] [PMID: 28183300]

[9] Waluyo A, Culbert GJ, Levy J, Norr KF. Understanding HIV-related stigma among Indonesian nurses. J Assoc Nurses AIDS Care 2015; 26(1): 69-80.

[http://dx.doi.org/10.1016/j.jana.2014.03.001] [PMID: 24759060]

[10] Röndahl G, Innala S, Carlsson M. Nursing staff and nursing students' attitudes towards HIV-infected and homosexual HIV-infected patients in Sweden and the wish to refrain from nursing. J Adv Nurs 2003; 41(5): 454-61.

[http://dx.doi.org/10.1046/j.1365-2648.2003.02553.x] [PMID: 12603570]

[11] Sirota T. Attitudes among nurse educators toward homosexuality. J Nurs Educ 2013; 52(4): 219-27.

[http://dx.doi.org/10.3928/01484834-20130320-01] [PMID: 23506172]

[12] Peate I, Suominen T, Välimäki M, Lohrmann C, Muinonen U. HIV/AIDS and its impact on student nurses. Nurse Educ Today 2002; 22(6): 492-501.

[http://dx.doi.org/10.1054/nedt.2002.0747] [PMID: 12387763]

[13] Watson J. Intentionality and caring-healing consciousness: A practice of transpersonal nursing. Holist Nurs Pract 2002; 16(4): 12-9. [http://dx.doi.org/10.1097/00004650-200207000-00005] 12060941]

[14] Earnshaw VA, Chaudoir SR. From conceptualizing to measuring HIV stigma: A review of HIV stigma mechanism measures. AIDS Behav 2009; 13(6): 1160-77.

[http://dx.doi.org/10.1007/s10461-009-9593-3] [PMID: 19636699]

[15] Mahajan AP, Sayles JN, Patel VA, et al. Stigma in the HIV/AIDS epidemic: A review of the literature and recommendations for the way forward. AIDS 2008; 22(Suppl. 2): S67-79.

[http://dx.doi.org/10.1097/01.aids.0000327438.13291.62] [PMID: 18641472]

[16] Goffman E. Stigma: Notes on the management of spoilt identity. Englewood Cliffs, NJ: Prentice Hall 1963.

[17] Turan B, Budhwani H, Fazeli PL, et al. How does stigma affect people living with HIV? The mediating roles of internalized and anticipated HIV stigma in the effects of perceived community stigma on health and psychosocial outcomes. AIDS Behav 2017; 21(1): 283-91. [http://dx.doi.org/10.1007/s10461-016-1451-5] [PMID: 27272742]

[18] Stantgor C. Handbook of prejudice, stereotyping and discrimination. New York, NY: Psychology Press 2009; pp. 1-22.

[19] Link BG, Phelan JC. Conceptualizing stigma. Annu Rev Sociol 2001; 27(1): 363-85.

[http://dx.doi.org/10.1146/annurev.soc.27.1.363]

[20] Dovidio JF, Hewstone M, Glick P, Esses VM. SAGE Handbook of Prejudice, Stereotyping, and Discrimination. Thousand Oaks, CA: SAGE Publications 2010.

[21] Leyva-Moral JM, Loayza-Enriquez BK, Palmieri PA, et al. Adherence to antiretroviral therapy and the associated factors among people living with HIV/AIDS in Northern Peru: A cross-sectional study. AIDS Res Ther 2019; 16(1): 22.

[http://dx.doi.org/10.1186/s12981-019-0238-y] [PMID: 31462291]

[22] Nyblade L, Srinivasan K, Mazur A, et al. HIV stigma reduction for health facility staff: Development of a blended-learning intervention. Front Public Health 2018; 6(165): 165.

[http://dx.doi.org/10.3389/fpubh.2018.00165] [PMID: 29977887]

[23] Leyva-Moral JM, de Dios Sánchez R, Lluva-Castaño A, MestresCamps L. Living with constant suffering: A different life following the diagnosis of HIV. J Assoc Nurses AIDS Care 2015; 26(5): 613-24. [http://dx.doi.org/10.1016/j.jana.2015.04.006] [PMID: 25998265]

[24] Bektaş HA, Kulakaç O. Knowledge and attitudes of nursing students toward patients living with HIV/AIDS (PLHIV): A Turkish perspective. AIDS Care 2007; 19(7): 888-94

[http://dx.doi.org/10.1080/09540120701203352] [PMID: 17712692]

[25] Earl CE. Thai nursing students' knowledge and health beliefs about AIDS and use of universal precautions: A cross-sectional descriptive research study. AAOHN J 2010; 58(8): 331-4.

[http://dx.doi.org/10.1177/216507991005800804] [PMID: 20669861]

[26] Bitton A, Fifield J, Ratcliffe H, et al. Primary healthcare system performance in low-income and middle-income countries: A scoping review of the evidence from 2010 to 2017. BMJ Glob Health 2019; 4(Suppl. 8).e001551

[http://dx.doi.org/10.1136/bmjgh-2019-001551] [PMID: 31478028]

[27] Li Y, Scott CS, Li L. Chinese nursing students' HIV/AIDS knowledge, attitudes, and practice intentions. Appl Nurs Res 2008; 21(3): 147-52. [http://dx.doi.org/10.1016/j.apnr.2006.10.004] [PMID: 18684408]

[28] Lohrmann C, Välimäki M, Suominen T, Muinonen U, Dassen T, Peate I. German nursing students' knowledge of and attitudes to HIV and AIDS: Two decades after the first AIDS cases. J Adv Nurs 2000; 31(3): 696-703.

[http://dx.doi.org/10.1046/j.1365-2648.2000.01326.x] [PMID: 10718890]

[29] Mueller CW, Cerny JE, Amundson MJ, Waldron JA. Nursing faculty and students' attitudes regarding HIV. J Nurs Educ 1992; 31(6): 273-9. [PMID: 1320109]

[30] Suominen T, Laakkonen L, Lioznov D, et al. Willingness to take care of HIV positive people: Responses from Russian nursing students. Nord J Nurs Res 2015; 35(2): 71-6. [http://dx.doi.org/10.1177/0107408314560323]

[31] Leyva-Moral JM, Terradas-Robledo R, Feijoo-Cid M, et al. Attitudes to HIV and AIDS among students and faculty in a school of nursing in Barcelona (Spain): A cross-sectional survey. Collegian 2017; 24(6): 593-601.

[http://dx.doi.org/10.1016/j.colegn.2016.10.006]

[32] Tanner CA. The teacher-proof curriculum. J Nurs Educ 1992; 31(6): 243-4. [PMID: 1320104] 
[33] Tanner CA. The meaning of curriculum: Content to be covered or stories to be heard? J Nurs Educ 2004; 43(1): 3-4 [http://dx.doi.org/10.3928/01484834-20040101-04]

[PMID: 14748528]

[34] Chuang AW, Nuthalapaty FS, Casey PM, et al. To the point: Reviews in medical education-taking control of the hidden curriculum. Am J Obstet Gynecol 2010; 203(4): 316.e1-6. [http://dx.doi.org/10.1016/j.ajog.2010.04.035] [PMID: 20541735]

[35] Thompson TL, Emrich K, Moore G. The effect of curriculum on the attitudes of nursing students toward disability. Rehabil Nurs 2003; 28(1): 27-30.

[http://dx.doi.org/10.1002/j.2048-7940.2003.tb01718.x] [PMID: 12567819]

[36] Cobos-Sanchiz D, Morón-Marchena JA, Reyes-Costales EM, LópezJarquín EJ. A propósito del sida: Un estudio cualitativo sobre percepción y actitudes de estudiantes y profesorado universitario en Chontales, Nicaragua. Poblac Salud Mesoam 2013; 10(2): 1-21.

[http://dx.doi.org/10.15517/psm.v10i2.8517]

[37] Méndez MA, Mejía MA, D’Avila MC. Actitud de docentes de licenciatura en Educación hacia SIDA. MedULA 2010; 19(2): 87-94.

[38] Pagliari AV, Garbin CAS, Garbin AJI. HIV attitudes and practices among professors in a Brazilian dental school. J Dent Educ 2004; 68(12): 1278-85.

[http://dx.doi.org/10.1002/j.0022-0337.2004.68.12.tb03878.x] [PMID: 15576817]

[39] Wagner AC, Hart TA, McShane KE, Margolese S, Girard TA. Health care provider attitudes and beliefs about people living with HIV: Initial validation of the Health Care Provider HIV/AIDS Stigma Scale (HPASS). AIDS Behav 2014; 18(12): 2397-408

[http://dx.doi.org/10.1007/s10461-014-0834-8] [PMID: 24965675]

[40] Xie H, Yu H, Watson R, et al. Cross-cultural validation of the health care provider HIV/AIDS stigma scale (HPASS) in China. AIDS Behav 2019; 23(4): 1048-56.

[http://dx.doi.org/10.1007/s10461-018-2312-1] [PMID: 30306438]

[41] Leyva-Moral JM, Dominguez-Cancino KA, Guevara-Vasquez GM, Edwards JE, Palmieri PA. Faculty attitudes about caring for people living with HIV/AIDS: A comparative study. J Nurs Educ 2019; 58(12): $712-7$

[http://dx.doi.org/10.3928/01484834-20191120-06] [PMID: 31794038]

[42] Palmieri PA, Leyva-Moral JM, Camacho-Rodriguez DE, et al. Hospital survey on patient safety culture (HSOPSC): A multi-method approach for target-language instrument translation, adaptation, and validation to improve the equivalence of meaning for cross-cultural research. BMC Nurs 2020; 19(1): 23.

[http://dx.doi.org/10.1186/s12912-020-00419-9] [PMID: 32308560]

[43] McCullagh P, Nelder JA. Generalized linear models. London, England: Chapman and Hall 1989.

[http://dx.doi.org/10.1007/978-1-4899-3242-6]

[44] Esarey J, Menger A. Practical and effective approaches to dealing with clustered data. Political Science Research and Methods 2019; 7(3): 541-59.

[http://dx.doi.org/10.1017/psrm.2017.42]

[45] Ibragimov R, Müller UK. t-Statistic based correlation and heterogeneity robust inference. J Bus Econ Stat 2010; 28(4): 453-68. [http://dx.doi.org/10.1198/jbes.2009.08046]

[46] R Core Development Team. R:. A language and environment for statistical computing 2017. Available from: https://www.R-project.org/

[47] StataCorp. Stata statistical software: Release 14 2015. Available from: https://www.stata.com/

[48] von Elm E, Altman DG, Egger M, Pocock SJ, Gøtzsche PC, Vandenbroucke JP. Strengthening the Reporting of Observational Studies in Epidemiology (STROBE) statement: Guidelines for reporting observational studies. BMJ 2007; 335(7624): 806-8. [http://dx.doi.org/10.1136/bmj.39335.541782.AD] [PMID: 17947786]

[49] Dyson J. Nurses' conceptualizations of caring attitudes and behaviours. J Adv Nurs 1996; 23(6): 1263-9.

[http://dx.doi.org/10.1046/j.1365-2648.1996.13326.x] [PMID: 8796477]

[50] Watson J. Nursing: The philosophy and science of caring. Boulder, CO: University Press of Colorado 2008.

[51] Eron LD. The effect of nursing education on attitudes. Nurs Res 1955; 4(1): $24-7$.

[http://dx.doi.org/10.1097/00006199-195506000-00003] [PMID: 14384085]

[52] Benner P. From novice to expert. Am J Nurs 1982; 82(3): 402-7. [PMID: 6917683]
[53] Bevis EO, Watson J. Toward a caring curriculum: A new pedagogy for nursing. New York, NY: National League for Nurses 1989.

[54] Watson J. Nursing: Human science and human care: A theory of nursing. Norwalk, CT: Appleton-Century-Crofts 1985.

[55] Farley JE, Hayat MJ, Murphy J, Sheridan-Malone E, Anderson J, Mark H. Knowledge, attitudes, and practices of OB/GYN nurses and auxiliary staff in the care of pregnant women living with HIV. J Assoc Nurses AIDS Care 2014; 25(2): 158-67.

[http://dx.doi.org/10.1016/j.jana.2013.04.004] [PMID: 23876818]

[56] Hamama L, Tartakovsky E, Eroshina K, et al. Nurses' job satisfaction and attitudes towards people living with HIV/AIDS in Russia. Int Nurs Rev 2014; 61(1): 131-9. [http://dx.doi.org/10.1111/inr.12074] [PMID: 24308493]

[57] Johnson M, Samarina A, Xi H, et al. Barriers to access to care reported by women living with HIV across 27 countries. AIDS Care 2015; 27(10): 1220-30.

[http://dx.doi.org/10.1080/09540121.2015.1046416]

[PMID: 26168817]

[58] Barrientos J. Situación social y legal de gays, lesbianas y personas transgénero y la discriminación contra estas poblaciones en América Latina. Sexualidad. Salud Soc 2016; 22: 331-54.

[59] Cianelli R, Ferrer L, McElmurry BJ. HIV prevention and low-income Chilean women: machismo, marianismo and HIV misconceptions. Cult Health Sex 2008; 10(3): 297-306. [http://dx.doi.org/10.1080/13691050701861439] [PMID: 18432428]

[60] Quevedo-Gómez MC, Krumeich A, Abadía-Barrero CE, PastranaSalcedo E, van den Borne H. machismo, public health and sexualityrelated stigma in Cartagena. Cult Health Sex 2012; 14(2): 223-35. [http://dx.doi.org/10.1080/13691058.2011.629682] [PMID: 22085396]

[61] Marín BV. HIV prevention in the Hispanic community: Sex, culture, and empowerment. J Transcult Nurs 2003; 14(3): 186-92.

[http://dx.doi.org/10.1177/1043659603014003005] [PMID: 12861921]

[62] Palmieri PA. A handbook for caring science: Expanding the paradigm. New York, NY: Springer Publishing Company 2019; pp. 493-510.

[63] Palmieri PA. Global advances in human caring literacy. New York, NY: Springer Publishing Company 2017; pp. 71-88.

[64] Kinyanda E, Weiss HA, Mungherera M, et al. Psychiatric disorders and psychosocial correlates of high HIV risk sexual behaviour in waraffected Eastern Uganda. AIDS Care 2012; 24(11): 1323-32. [http://dx.doi.org/10.1080/09540121.2011.647676] [PMID: 22272693]

[65] Labrague LJ, McEnroe-Petitte DM, Papathanasiou IV, Edet OB, Arulappan J. Impact of instructors' caring on students' perceptions of their own caring behaviors. J Nurs Scholarsh 2015; 47(4): 338-46.

[http://dx.doi.org/10.1111/jnu.12139] [PMID: 25959595]

[66] Camillo SdeO, Maiorino FT, Chaves LC. O ensino de enfermagem sobre HIV/AIDS sob a ótica da cidadania. Rev Gaúcha Enferm 2013; 34(3): 117-23.

[http://dx.doi.org/10.1590/S1983-14472013000300015] [PMID: 24344593]

[67] Feijoo-Cid M, Moriña D, Gómez-Ibáñez R, Leyva-Moral JM. Expert patient illness narratives as a teaching methodology: A mixed method study of student nurses satisfaction. Nurse Educ Today 2017; 50: 1-7. [http://dx.doi.org/10.1016/j.nedt.2016.11.029] [PMID: 27998806]

[68] Davidson L. Recovery, self management and the expert patient Changing the culture of mental health from a UK perspective. J Ment Health 2005; 14(1): 25-35.

[http://dx.doi.org/10.1080/09638230500047968]

[69] Worthington CA, O'Brien KK, Mill J, Caine V, Solomon P, ChawKant J. A mixed-methods outcome evaluation of a mentorship intervention for Canadian nurses in HIV care. J Assoc Nurses AIDS Care 2016; 27(5): 677-97.

[http://dx.doi.org/10.1016/j.jana.2016.02.011] [PMID: 27039195]

[70] Jaworsky D, Gardner S, Thorne JG, et al. The role of people living with HIV as patient instructors - reducing stigma and improving interest around HIV care among medical students. AIDS Care 2017; 29(4): 524-31.

[http://dx.doi.org/10.1080/09540121.2016.1224314]

[PMID: 27577683.

[71] Hoseinpour AM, Moghadam ZE, Saeidi M. The knowledge and attitude of teachers about HIV/AIDS; before and after training in Khorasan Razavi Province, Iran. International Journal of Pediatrics 2015; 3(6.2): 1161-68.

[72] Lohmann T, Tam P, Hopman WM, Wobeser W. Knowledge of and attitudes towards HIV/AIDS among school teachers in Belize. Int $\mathrm{J}$ Infect Dis 2009; 13(5): e228-35.

[http://dx.doi.org/10.1016/j.ijid.2008.11.023] [PMID: 19250849]

[73] Parahoo K. Nursing research Principles, process, and issues. 3rd ed. 
Houndmills, UK: Red Globe Press 2014.

[74] Waltz CF, Strickland OL, Lenz ER, Eds. Measurement in nursing and health research. New York, NY: Springer Publishing Company 2016 [http://dx.doi.org/10.1891/9780826170620]

\section{(C) 2020 Leyva-Moral et al.}

This is an open access article distributed under the terms of the Creative Commons Attribution 4.0 International Public License (CC-BY 4.0), a copy of which is available at: https://creativecommons.org/licenses/by/4.0/legalcode. This license permits unrestricted use, distribution, and reproduction in any medium, provided the original author and source are credited. 